\title{
VARIABILIDADE DE ATRIBUTOS FÍSICOS E QUÍMICOS DE SOLOS DA FORMAÇÃO GUABIROTUBA EM DIFERENTES UNIDADES DE AMOSTRAGEM(1)
}

\author{
Jairo Calderari de Oliveira Junior( ${ }^{(2)}$, Luiz Claudio de Paula Souza ${ }^{(3)}$ \\ $\&$ Vander de Freitas Melo ${ }^{(4)}$
}

\begin{abstract}
RESUMO
A amostragem do solo é uma importante etapa para caracterização dos atributos físicos e químicos de uma área e definir práticas de manejo e adubação. Para isso, usualmente é utilizada amostragem composta, que busca a representação da área por meio da homogeneização de amostras simples, e, assim, a subdivisão da área em glebas homogêneas assume um importante papel. Os objetivos deste trabalho foram avaliar a variabilidade dos atributos químicos $\left(\mathrm{pH}, \mathrm{Ca}^{2+}, \mathrm{Mg}^{2+}, \mathrm{Al}^{3+}\right.$, K, P, H e C orgânico) e físicos do solo (areia grossa, areia fina, silte e argila) em uma população de amostras em diferentes níveis de subdivisão das glebas e verificar a confiabilidade da amostragem composta da área. A área do estudo situa-se na Fazenda Experimental do Canguiri, da Universidade Federal do Paraná, Curitiba (PR). A coleta das amostras foi realizada numa gleba de 12,88 ha, com espaçamento de $30 \mathrm{~m}$, totalizando 135 amostras simples. Os dados foram analisados por medidas de dispersão e normalidade, tomando os seguintes níveis de subdivisão: (a) área total $(n=135)$; (b) compartimentos geomorfológicos: inferior $(n=38)$, médio $(n=60)$ e superior ( $\mathrm{n}=37)$; e (c) subdivisão dos compartimentos em unidades de mapeamento: inferior - três unidades, médio - quatro unidades, superior - três unidades. Os atributos que apresentaram maior variabilidade foram $\mathrm{Al}^{3+}, \mathrm{P} \mathrm{e} \mathrm{K}^{+}$. Com maior subdivisão, da área, os parâmetros estatísticos mostraram menor variação dos dados. Para o $\mathrm{Al}^{3+}$, por exemplo, com a maior subdivisão os valores de amplitude (diferença percentual entre o valor mínimo e o máximo) passaram de $3.895 \%$ para 294 \%, mostrando a importância dos critérios utilizados na subdivisão das glebas. Em áreas com relevo mais acidentado, mesmo a coleta de amostra composta por compartimento ou por unidade de mapeamento não garantiu a homogeneidade da amostragem. A distribuição dos dados para a maioria dos atributos em área total e
\end{abstract}

\footnotetext{
(1) Recebido para publicação em outubro de 2009 e aprovado em agosto de 2010.

(2) Mestrando em Ciência do Solo, Universidade Federal do Paraná - UFPR. Rua dos Funcionários 1540, Juvevê, CEP 80035-050 Curitiba (PR). E-mail: jairo@agronomo.eng.br

(3) Departamento de Solos e Engenharia Agrícola, UFPR. E-mail: lcsouza@ufpr.br

(4) Departamento de Solos e Engenharia Agrícola, UFPR. Bolsista CNPq. E-mail: vanderfm@ufpr.br
} 
em compartimentos geomorfológicos não seguiu a distribuição normal, restringindo o uso da amostragem composta nessas condições, ao contrário do observado quando a área foi subdividida em unidades de mapeamento.

Termos de indexação: amostragem composta, variabilidade amostral, coeficiente de variação, distribuição normal.

\title{
SUMMARY: VARIABILITY OF SOIL PHYSICALAND CHEMICAL PROPERTIES IN DIFFERENT PLOT DIVISIONS OF THE GUABIROTUBA FORMATION
}

\begin{abstract}
Soil sampling is an important part of soil physical and chemical characterization underlying management and fertilization practices. For this purpose, composite sampling is largely used in order to represent the area by the homogenization of single samples. Consequently, the subdivision of the area in homogeneous plots plays an important role. The aim of this study was to evaluate the variability of soil chemical ( $\mathrm{pH} ; \mathrm{Ca}^{2+} ; \mathrm{Mg}^{2+} ; \mathrm{Al}^{3+} ; \mathrm{K} ; \mathrm{P} ; \mathrm{H}$; organic carbon) and physical properties (coarse sand, fine sand, silt, and clay) in a sample set at different subdivision levels and to verify the reliability of the composite sample of the area. The study area is part of the Experimental Farm Canguiri of the Federal University of Paraná, Curitiba (PR). Soil sampling was performed in an area of 12.88 ha at points $30 \mathrm{~m}$ away from each other, resulting in 135 simple samples. Data were analyzed by dispersion and normality parameters, using the following subdivision levels: (a) total area $(n=135)$; (b) geomorphological compartments: lower $(n=38)$, medium $(n=60)$, upper $(n=37) ;(c)$ compartment division in mapping units: lower -3 units, medium - 4 units, upper -3 units. $A l^{3+}, P$ and $K^{+}$were the properties with highest variability. With increasing area subdivision, the statistical parameters showed less data variation. For $\mathrm{Al}^{3+}$, for example, at the highest level of subdivision, the amplitude values (percentage difference between highest and lowest values) decreased from 3.895 to $294 \%$, indicating the importance of the criteria underlying plot division. In areas with higher slope, even the composite sampling based on geomorphological compartments or mapping units did not ensure the sampling quality. For most properties in the total area and geomorphological compartments, the data distribution was not normal, limiting the use of composite sampling under these conditions, although the opposite was observed when the area was subdivided into mapping units.
\end{abstract}

Index terms: composite sampling, sample variability, coefficient of variation, normal distribution.

\section{INTRODUÇÃO}

Vários estudos de amostragem têm sido realizados visando reduzir a variabilidade das características do solo: influência do instrumento de coleta (trado, pá de corte, etc.) (Alvarez V. \& Guarçoni M., 2003; Guarçoni et al., 2007; Oliveira et al., 2007); número de amostras simples necessárias para formar uma composta (Souza et al., 1997; Alvarez V. \& Guarçoni M., 2003; Carvalho et al., 2002; Silva et al., 2003a; Oliveira et al., 2007; Amaro Filho et al., 2007; Brus \& Noij, 2008; Weindorf \& Zhu, 2010); efeito dos tratos culturais (Silveira et al., 2000; Guarçoni et al., 2007; Oliveira et al., 2007; Pauletti et al., 2009); interferência das pedoformas (Souza et al., 2003; Montanari et al., 2005; Souza et al., 2006; Sanchez et al., 2009); e escalas de amostragem (Lin et al., 2005; Wang et al., 2008). Contudo, nesses estudos, normalmente, não se consideram a variabilidade das amostras simples na composição da amostra composta e a forma como as glebas são definidas, o que pode comprometer a confiabilidade das análises e as práticas culturais.

Delimitar uma gleba homogênea é um passo importante para a amostragem dos solos e representatividade da área, devendo-se levar em conta a vegetação, posição topográfica, características do solo e histórico de utilização da área (Cantarutti et al., 1999; SBCS, 2004). Entretanto, a alta variabilidade do solo, mesmo em áreas com características aparentemente uniformes, dificulta a amostragem representativa (Silveira et al., 2000; Souza et al., 2003; Souza et al., 2006; Barbar \& Melo, 2008; Zorzi et al., 2008), tornando-se a maior fonte de incerteza dos resultados - maior até que o preparo, manuseio e a análise de laboratório (Lambkin et al., 2004). Solos originados da Formação Guabirotuba possuem naturalmente grande variabilidade nos seus atributos físicos, químicos e mineralógicos (Kraemer, 2007; Barbar \& Melo, 2008), devendo-se ter maior cuidado na divisão de glebas para amostragem e caracterização da área. 
A amostragem composta de solos tem como premissa que a média aritmética das amostras simples é similar ao valor da amostra composta (Oliveira et al., 2007), considerando, então, que os indivíduos que a compuseram tenham distribuição igual à normal; nesse caso, a população pode ser representada pela média e pelo desvio-padrão (Snedecor \& Cochran, 1967). Guarçoni et al. (2007), Machado et al. (2007), Guedes Filho et al. (2010) e Silva et al. (2010) encontraram distribuição normal para a maioria dos atributos do solo, ao contrário de outros autores: Souza et al. (1997), apenas para o P e umidade gravimétrica; Silva \& Chaves (2001), somente para K; e Souza et al. (1999) e Montezano et al. (2006), distribuição não normal para a maioria dos atributos do solo. Com a coleta de uma amostra composta, torna-se impossível determinar a distribuição dos indivíduos. Caso a população não siga uma distribuição normal, a média (obtida das amostras simples ou o valor da amostra composta) não pode ser considerada a melhor medida de representação da população (Amaro Filho et al., 2007; Rosa Filho et al., 2009).

O coeficiente de variação $(\mathrm{CV})$, obtido pela razão entre desvio-padrão e a média dos dados, é uma importante ferramenta para análise da dispersão dos dados por ser uma medida relativa ao valor médio da série, possibilitando comparar dados com unidades de medida e médias diferentes. Já o desvio-padrão, que é uma medida de dispersão absoluta, é limitado na comparação de dados expressos em diferentes unidades. Segundo Warrick \& Nielsen (1980), o CV para os atributos do solo, mesmo em áreas homogêneas, pode variar de 10 até mais de $1.000 \%$, sendo elas classificadas em três níveis: baixa (CV $\leq 12 \%)$, média $(12 \%<\mathrm{CV} \leq 52 \%)$ e alta $(\mathrm{CV}>52 \%)$. Vanni (1998) colocou limites menos restritivos para esse parâmetro: CV $<35 \%$ - média representativa e série de dados homogêneos; CV entre 35 e $65 \%$ - série de dados heterogênea e média pouco significativa; e CV > $65 \%$ - série de dados muito heterogênea e média sem nenhum significado. Como exemplos de aplicação dos valores de CV, Montanari et al. (2005) e Souza et al. (2006) estudaram a influência das pedoformas na variabilidade dos atributos do solo e observaram que pedoformas côncavas necessitavam de maior número de amostras para representar sua variabilidade, quando comparadas com pedoformas retilíneas, ou seja, maior CV da primeira pedoforma. O P e o K foram os atributos com maiores variações nas pedoformas (maior CV), principalmente na camada superficial, reforçando os trabalhos de Souza et al. (1999), Carvalho et al. (2002), Alvares \& Garçoni (2003) e Silva et al. (2003a).

Este trabalho teve como objetivos avaliar a variabilidade dos atributos químicos $\left(\mathrm{pH}, \mathrm{Ca}^{2+}, \mathrm{Mg}^{2+}\right.$, $\mathrm{Al}^{3+}, \mathrm{K}, \mathrm{P}, \mathrm{H}$ e C orgânico) e físicos do solo (areia grossa, areia fina, silte e argila) em uma população de amostras em diferentes níveis de subdivisão das glebas e verificar a confiabilidade da amostragem composta da área.

\section{MATERIAL E MÉTODOS}

A área de estudo está situada na Fazenda Experimental do Canguiri (CEEX), da Universidade Federal do Paraná (UFPR), no município de Pinhais, região metropolitana de Curitiba (PR), entre as coordenadas geográficas: $-25^{\circ} 22^{\prime} 38^{\prime \prime}$ e $-25^{\circ} 24^{\prime} 46^{\prime \prime}$ de latitude sul, $-49^{\circ} 09^{\prime} 05^{\prime \prime}$ e $-49^{\circ} 06^{\prime} 40^{\prime \prime}$ de longitude oeste, com altitude média de $920 \mathrm{~m}$. O material de origem é a Formação Guabirotuba, composto por argilito, seguindo-se de arcósios e depósitos rudáceos, além de pequenos horizontes de caliche (Salamuni \& Stellfeld, 2001). Os solos derivados desse material são predominantemente Cambissolos álicos, Latossolos Vermelho-Amarelos álicos e Solos Orgânicos (Embrapa, 1984).

Foram coletadas 135 amostras simples da área de estudo, em 12,88 ha. A coleta de amostras do horizonte A foi realizada por um trado mecânico com um tubo de PVC no seu interior, acoplado à tomada de potência de um trator. As amostras foram secas ao ar e passadas em peneira de $2 \mathrm{~mm}$ para caracterização química (Embrapa, 1997): pH em água e em KCl $1 \mathrm{~mol} \mathrm{~L}^{-1} ; \mathrm{Ca}^{2+}, \mathrm{Mg}^{2+} \mathrm{e} \mathrm{Al}^{3+}$ trocáveis $\left(\mathrm{KCl} 1 \mathrm{~mol} \mathrm{~L}^{-1}\right)$; $\mathrm{K}^{+}$trocável e $\mathrm{P}$ disponível (Mehlich-1); $\mathrm{H}$ - acidez potencial (acetato de Ca $1 \mathrm{~mol} \mathrm{~L}^{-1} \mathrm{pH}$ 7,0); C orgânico (método espectrofotométrico). A textura foi determinada pelo método do densímetro, e as frações areia grossa e fina, por tamisamento (Embrapa, 1997).

Para análise da variabilidade dos atributos químicos e físicos do solo, a área total foi primeiramente subdividida em três glebas, levando em consideração o relevo, o uso atual e o histórico da área: compartimento superior, compartimento médio e compartimento inferior (Figura 1a).

Em um nível de maior subdivisão das glebas, foram utilizadas as 10 unidades de mapeamento, na escala 1:10.000, descritas por Kraemer (2007) (Figura 1b): Un1 - Latossolo Vermelho distrófico húmico textura muito argilosa; Un2 - Latossolo Vermelho-Amarelo distrófico húmico textura argilosa; Un3 - Cambissolo Húmico distrófico textura muito argilosa; Un4 - associação Cambissolo Húmico distrófico latossólico textura argilosa + Cambissolo Háplico Tb distrófico textura argilosa; Un5 - associação Cambissolo Háplico Tb distrófico latossólico textura argilosa + Cambissolo Húmico Alumínico latossólico textura argilosa; Un6-Cambissolo Húmico distrófico latossólico textura argilosa; Un7 Cambissolo Húmico alumínico latossólico textura argilosa; Un8 - associação Cambissolo Húmico distrófico latossólico textura argilosa + Cambissolo Háplico $\mathrm{Tb}$ distrófico latossólico textura argilosa; Un9 Cambissolo Húmico distrófico latossólico textura argilosa; e Un10 - Cambissolo Húmico distrófico latossólico textura argilosa. Devido à incompatibilidade dos limites das áreas das unidades e dos compartimentos (Figura 1a,b), algumas unidades se posicionaram em dois compartimentos simultaneamente. Por exemplo, no quadro 1, a unidade 8, mesmo apresentando pequena proporção de área no compartimento superior, foi incluída no compartimento médio. 

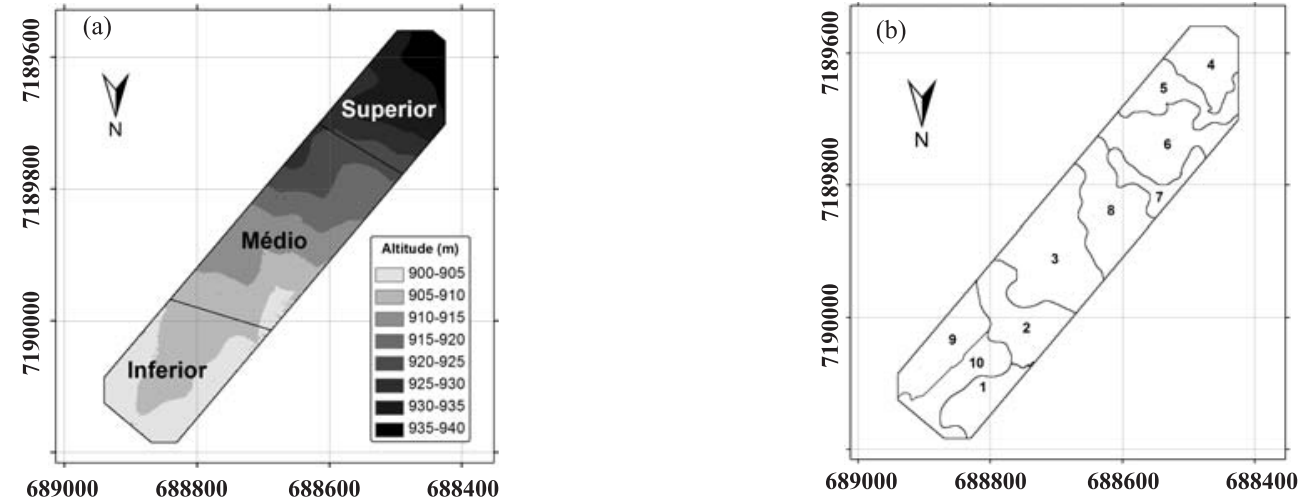

Figura 1. (a) Altitudes da área de estudo e subdivisões por geomorfologia e uso atual: inferior, médio e superior. (b) Unidades de Mapeamento: 1 a 10, descritas por Kraemer (2007).

Quadro 1. Valores mínimos, máximos e a média das características físicas e químicas das amostras do horizonte A em cada subdivisão(1)

\begin{tabular}{|c|c|c|c|c|c|c|c|c|c|c|c|c|c|c|c|}
\hline \multirow[b]{2}{*}{ Amostras (n) } & & Total & Inf. & Un 1 & Un 9 & Un 10 & Médio & Un 2 & Un 3 & Un 7 & Un 8 & Sup. & Un 4 & Un 5 & Un 6 \\
\hline & & 135 & 38 & 8 & 13 & 10 & 60 & 15 & 25 & 11 & 13 & 37 & 13 & 14 & 13 \\
\hline \multirow{3}{*}{$\mathrm{pH}$ água } & Mín. & 5,1 & 5,1 & 5,1 & 5,2 & 5,3 & 5,1 & 5,3 & 5,2 & 5,1 & 5,3 & 5,1 & 5,3 & 5,1 & 5,2 \\
\hline & Máx. & 6,4 & 6,3 & 5,8 & 6,3 & 5,8 & 6,3 & 6,3 & 6,2 & 6,0 & 6,0 & 6,4 & 6,2 & 5,8 & 6,4 \\
\hline & Méd. & 5,6 & 5,5 & 5,5 & 5,5 & 5,5 & 5,6 & 5,6 & 5,7 & 5,5 & 5,7 & 5,5 & 5,7 & 5,4 & 5,5 \\
\hline \multirow{3}{*}{$\mathrm{pH} \mathrm{KCl}$} & Mín. & 4,1 & 4,4 & 4,4 & 4,4 & 4,6 & 4,1 & 4,4 & 4,1 & 4,2 & 4,4 & 4,1 & 4,5 & 4,1 & 4,2 \\
\hline & Máx. & 5,6 & 5,6 & 5,1 & 5,6 & 5,2 & 5,5 & 5,2 & 5,1 & 5,0 & 5,5 & 5,3 & 5,3 & 5,0 & 4,9 \\
\hline & Méd. & 4,7 & 4,8 & 4,8 & 4,7 & 4,8 & 4,7 & 4,7 & 4,6 & 4,5 & 4,8 & 4,6 & 4,8 & 4,5 & 4,5 \\
\hline \multirow{3}{*}{$\begin{array}{c}\mathrm{Al}^{3+} \\
\left(\mathrm{cmol}_{\mathrm{c}} \mathrm{dm}^{-3}\right)\end{array}$} & Mín. & 0,10 & 0,10 & 0,10 & 0,10 & 0,10 & 0,10 & 0,11 & 0,10 & 0,11 & 0,12 & 0,10 & 0,10 & 0,11 & 0,13 \\
\hline & Máx. & 4,05 & 1,37 & 0,88 & 1,37 & 0,40 & 3,67 & 1,09 & 2,05 & 3,67 & 1,18 & 4,05 & 1,37 & 2,94 & 4,05 \\
\hline & Méd. & 0,66 & 0,42 & 0,27 & 0,56 & 0,22 & 0,49 & 0,58 & 0,37 & 1,16 & 0,41 & 1,18 & 0,41 & 1,09 & 1,63 \\
\hline \multirow{3}{*}{$\begin{array}{c}\mathrm{Ca}^{2+} \\
\left(\mathrm{cmol}_{\mathrm{c}} \mathrm{dm}^{-3}\right)\end{array}$} & Mín. & 1,09 & 3,03 & 3,33 & 3,07 & 3,75 & 1,61 & 3,03 & 2,69 & 1,61 & 4,15 & 1,09 & 2,73 & 1,22 & 1,09 \\
\hline & Máx. & 11,05 & 11,05 & 6,84 & 7,54 & 11,05 & 8,70 & 9,05 & 8,70 & 6,33 & 7,70 & 7,51 & 7,33 & 7,51 & 6,80 \\
\hline & Méd. & 5,17 & 5,66 & 5,23 & 5,45 & 6,08 & 5,59 & 5,99 & 5,76 & 4,20 & 5,68 & 4,00 & 5,32 & 3,93 & 3,61 \\
\hline \multirow{3}{*}{$\begin{array}{c}\mathrm{Mg}^{2+} \\
\left(\mathrm{cmol}_{\mathrm{c}} \mathrm{dm}^{-3}\right)\end{array}$} & Mín. & 0,41 & 0,68 & 1,58 & 0,68 & 2,18 & 1,15 & 1,63 & 1,33 & 1,15 & 1,78 & 0,41 & 1,76 & 0,94 & 0,41 \\
\hline & Máx. & 4,67 & 4,67 & 4,28 & 4,11 & 4,67 & 4,52 & 4,36 & 4,52 & 4,05 & 4,21 & 4,12 & 3,39 & 4,12 & 4,00 \\
\hline & Méd. & 2,71 & 2,97 & 3,01 & 2,62 & 3,30 & 2,91 & 3,06 & 2,91 & 2,61 & 2,73 & 2,10 & 2,48 & 2,33 & 2,05 \\
\hline \multirow{3}{*}{$\begin{array}{c}\mathrm{K}^{+} \\
\left(\mathrm{cmol}_{\mathrm{c}} \mathrm{dm}^{-3}\right)\end{array}$} & Mín. & 0,02 & 0,05 & 0,08 & 0,05 & 0,06 & 0,02 & 0,04 & 0,02 & 0,06 & 0,07 & 0,04 & 0,05 & 0,04 & 0,04 \\
\hline & Máx. & 0,66 & 0,60 & 0,35 & 0,60 & 0,22 & 0,66 & 0,36 & 0,66 & 0,39 & 0,64 & 0,55 & 0,41 & 0,55 & 0,29 \\
\hline & Méd. & 0,18 & 0,15 & 0,15 & 0,17 & 0,11 & 0,20 & 0,18 & 0,25 & 0,15 & 0,18 & 0,17 & 0,17 & 0,19 & 0,13 \\
\hline \multirow{3}{*}{$\begin{array}{c}\mathrm{P} \\
\left(\mathrm{mg} \mathrm{dm}^{-3}\right)\end{array}$} & Mín. & 0,29 & 0,29 & 0,29 & 1,93 & 1,23 & 0,41 & 1,97 & 0,41 & 1,11 & 1,62 & 0,45 & 0,83 & 0,45 & 0,63 \\
\hline & Máx. & 36,87 & 8,61 & 8,61 & 6,90 & 5,15 & 36,87 & 6,92 & 17,64 & 7,49 & 36,87 & 9,36 & 3,18 & 9,36 & 5,98 \\
\hline & Méd. & 3,80 & 3,28 & 2,87 & 3,87 & 2,76 & 4,83 & 3,82 & 5,11 & 3,07 & 6,33 & 2,65 & 2,05 & 3,76 & 2,41 \\
\hline \multirow{3}{*}{$\begin{array}{c}\mathrm{H} \\
\left(\mathrm{cmol}_{\mathrm{c}} \mathrm{dm}^{-3}\right)\end{array}$} & Mín. & 3,30 & 3,66 & 3,66 & 5,52 & 5,66 & 4,03 & 4,74 & 5,28 & 4,71 & 4,03 & 3,30 & 3,30 & 5,20 & 5,02 \\
\hline & Máx. & 14,72 & 11,44 & 7,89 & 10,93 & 8,69 & 11,81 & 11,44 & 11,81 & 9,47 & 9,15 & 14,72 & 12,05 & 14,72 & 8,97 \\
\hline & Méd. & 7,39 & 7,23 & 5,75 & 8,11 & 7,15 & 7,32 & 7,92 & 7,59 & 7,57 & 6,29 & 7,66 & 7,04 & 8,14 & 7,36 \\
\hline \multirow{3}{*}{$\begin{array}{c}\mathrm{CO} \\
\left(\mathrm{g} \mathrm{dm}^{-3}\right)\end{array}$} & Mín. & 8,25 & 8,25 & 24,73 & 30,77 & 8,25 & 8,90 & 29,94 & 26,09 & 8,90 & 26,99 & 14,28 & 14,28 & 25,20 & 27,70 \\
\hline & Máx. & 54,86 & 48,29 & 38,81 & 48,29 & 42,50 & 47,31 & 45,35 & 47,31 & 40,08 & 44,69 & 54,86 & 54,86 & 51,75 & 41,22 \\
\hline & Méd. & 35,59 & 35,69 & 31,69 & 38,00 & 34,71 & 35,40 & 37,79 & 37,06 & 31,53 & 34,25 & 35,80 & 35,37 & 37,53 & 33,79 \\
\hline \multirow{3}{*}{$\begin{array}{l}\text { Argila } \\
\left(\mathrm{g} \mathrm{kg}^{-1}\right)\end{array}$} & Mín. & 260 & 353 & 541 & 458 & 390 & 335 & 522 & 399 & 410 & 372 & 260 & 363 & 260 & 425 \\
\hline & Máx. & 670 & 597 & 605 & 598 & 587 & 607 & 639 & 634 & 586 & 657 & 670 & 523 & 558 & 670 \\
\hline & Méd. & 518 & 436 & 583 & 543 & 509 & 470 & 584 & 534 & 482 & 496 & 504 & 444 & 487 & 515 \\
\hline \multirow{3}{*}{$\begin{array}{c}\text { Silte } \\
\left(\mathrm{g} \mathrm{kg}^{-1}\right)\end{array}$} & Mín. & 325 & 390 & 386 & 393 & 400 & 372 & 353 & 355 & 402 & 335 & 325 & 466 & 433 & 325 \\
\hline & Máx. & 716 & 639 & 449 & 529 & 597 & 657 & 469 & 589 & 580 & 607 & 716 & 616 & 716 & 558 \\
\hline & Méd. & 470 & 552 & 406 & 446 & 477 & 519 & 406 & 456 & 505 & 491 & 483 & 541 & 500 & 472 \\
\hline \multirow{3}{*}{$\begin{array}{c}\mathrm{AF} \\
\left(\mathrm{g} \mathrm{kg}^{-1}\right)\end{array}$} & Mín. & 2 & 3 & 6 & 4 & 7 & 2 & 3 & 2 & 6 & 5 & 3 & 4 & 5 & 3 \\
\hline & Máx. & 14 & 10 & 9 & 8 & 10 & 11 & 7 & 8 & 9 & 11 & 14 & 14 & 11 & 11 \\
\hline & Méd. & 7 & 7 & 7 & 7 & 8 & 6 & 5 & 5 & 7 & 7 & 9 & 10 & 8 & 7 \\
\hline \multirow{3}{*}{$\begin{array}{c}\mathrm{AG} \\
\left(\mathrm{g} \mathrm{kg}^{-1}\right)\end{array}$} & Mín. & 2 & 3 & 4 & 3 & 4 & 2 & 3 & 2 & 4 & 3 & 2 & 3 & 2 & 3 \\
\hline & Máx. & 14 & 9 & 5 & 6 & 9 & 14 & 8 & 11 & 9 & 14 & 13 & 8 & 13 & 12 \\
\hline & Méd. & 5 & 5 & 4 & 5 & 5 & $\begin{array}{r}14 \\
5\end{array}$ & 4 & 5 & 6 & 7 & 5 & 5 & 5 & 6 \\
\hline \multirow{3}{*}{$\begin{array}{c}\mathrm{AT} \\
\left(\mathrm{g} \mathrm{kg}^{-1}\right)\end{array}$} & Mín. & 6 & 8 & 10 & 8 & 12 & 6 & 7 & 6 & 10 & 7 & 6 & 7 & 9 & 6 \\
\hline & Máx. & 24 & 19 & 15 & 14 & 19 & 21 & 12 & 17 & 17 & 21 & 24 & 23 & 24 & 18 \\
\hline & Méd. & 12 & 12 & 11 & 11 & 14 & 11 & 10 & 10 & 13 & 14 & 14 & 15 & 13 & 13 \\
\hline
\end{tabular}

(1) A localização da área e a hierarquia das subdivisões são apresentadas nas figuras 1a,b. Total: área total subdividida nos compartimentos inferior, médio e superior. Inf.: compartimento inferior subdividido nas unidades de mapeamento 1,9 e 10 . Médio: compartimento médio subdividido nas unidades de mapeamento 2, 3, 7 e 8. Sup.: compartimento superior subdividido nas unidades de mapeamento 4, 5 e 6. AF: areia fina; AG: areia grossa; AT: areia total. O número de amostras para as unidades de mapeamento difere do número total do compartimento devido à incompatibilidade dos limites das áreas das unidades e dos compartimentos; assim, algumas unidades posicionaram-se em dois compartimentos simultaneamente. 
O número de amostras para cada subdivisão foi diferente (Quadro 1), uma vez que o tamanho das áreas não foi igual (Figura 1a,b). Utilizando o programa Statistica for Windows (Statsoft, 2007), foram obtidos valores máximos, mínimos, média, coeficiente de variação, assimetria, curtose e Shapiro-Wilk. Utilizou-se a análise de correlação linear simples (Pearson) para verificar a relação de causa/efeito entre os atributos físicos e químicos dos solos na área total e em suas subdivisões.

Para analisar a distribuição dos dados, foram calculados os coeficientes de assimetria, curtose e feito o teste de Shapiro-Wilk. Caso a distribuição dos dados seguisse o tipo normal, a coleta de uma amostra composta teria boa representatividade da área; caso contrário, a utilização da amostragem composta poderia incorrer em erro na estimativa dos valores para os atributos na área (Rosa Filho et al., 2009). A distribuição normal foi indicada quando os valores de coeficiente de assimetria e curtose foram 0 e 3, respectivamente (Snedecor \& Cochran, 1967), e o valor de $\mathrm{p}$ calculado no teste de Shapiro-Wilk foi maior que 0,05 .

Quanto à análise da amplitude dos dados, esta foi expressa em percentagem, possibilitando a comparação entre atributos com diferentes unidades de medida, como, por exemplo, $\mathrm{Al}^{3+}$ e CO. Para o cálculo da amplitude dos dados em percentagem, usou-se a expressão: [[(máximo/mínimo)-1]x100].

\section{RESULTADOS E DISCUSSÃO}

O quadro 1 mostra os valores mínimo, máximo e a média, obtidos para cada atributo nos diferentes compartimentos de amostragem, indicando também o número de amostras que compôs cada compartimento. O menor número de amostras observado foi para a unidade de mapeamento 1 (Un 1), com oito amostras, o que, segundo Oliveira et al. (2007), é suficiente para formar uma amostra composta.

A amplitude dos valores de cada atributo químico diminuiu à medida que a área total foi subdividida (Quadro 2). Tomando o C orgânico (CO) como exemplo, na área total $(\mathrm{n}=135)$ a amplitude entre o maior e $\mathrm{o}$ menor valor foi de $565 \%$; nos compartimentos inferior, médio e superior, foram de 485, 432 e $284 \%$, respectivamente. Em áreas mais homogêneas, os valores de amplitude das unidades foram ainda inferiores aos observados para seu respectivo compartimento (inferior - entre 57 e $415 \%$; médio entre 51 e $350 \%$; superior - entre 49 e $284 \%$ ).

O compartimento superior, em relação aos demais, apresentou maiores valores de amplitude e de coeficiente de variação para a grande maioria dos atributos (Quadros 2 e 3). O relevo ondulado predominante nesse compartimento permitiu a formação de microrrelevos (observações de campo) com curvaturas côncavas e convexas com drenagens diferenciadas, as quais, provavelmente, ampliaram as variações dos atributos e dificultaram a representatividade da área mesmo com

Quadro 2. Amplitude dos atributos, em percentagem, na área total (total) e compartimentos inferior (composto pelas unidades de mapeamento 1, 9 e 10), médio (composto pelas unidades $2,3,7$ e 8 ) e superior (composto pelas unidades 4,5 e 6$)^{(1)}$

\begin{tabular}{|c|c|c|c|c|c|c|c|c|c|c|c|c|c|c|}
\hline & Total & Inf. & Un 1 & Un 9 & Un 10 & Médio & Un 2 & Un 3 & Un 7 & Un 8 & Sup. & Un 4 & Un 5 & Un 6 \\
\hline pH água & 26 & 25 & 15 & $23^{* *}$ & $10 *$ & $23^{+}$ & $20^{* *}$ & 19 & 18 & $15^{*}$ & $26^{++}$ & 17 & $15^{*}$ & $22^{* *}$ \\
\hline $\mathrm{pH} \mathrm{K}$ & 37 & $27^{+}$ & 17 & $27 * *$ & $13^{*}$ & $35^{++}$ & 20 & 25 & $19 *$ & $26^{* *}$ & 28 & 19 & $21^{* *}$ & $18^{*}$ \\
\hline $\mathrm{Al}^{3+}$ & 3.895 & $1.256^{+}$ & 756 & $1.236^{* *}$ & $294^{*}$ & 1.905 & 902 & 1.905 & $3.246^{* *}$ & $881^{*}$ & $3.877^{++}$ & $1246^{*}$ & 2.603 & $3.061 * *$ \\
\hline $\mathrm{Ca}^{2+}$ & 912 & 265 & $105^{*}$ & 146 & $195^{* *}$ & $223^{+}$ & 199 & 223 & $293^{* *}$ & $86^{*}$ & $587^{++}$ & $169^{*}$ & 517 & $523^{* *}$ \\
\hline $\mathrm{Mg}^{2+}$ & 1.051 & 585 & 170 & $503^{* *}$ & $114^{*}$ & $241^{+}$ & 168 & 241 & $253^{* *}$ & $137^{*}$ & $916^{++}$ & $93^{*}$ & 338 & $888^{* *}$ \\
\hline $\mathrm{K}^{+}$ & 3.978 & $1.056^{+}$ & 340 & $1.056^{* *}$ & $261^{*}$ & $3.978^{++}$ & 743 & $3.978^{* *}$ & $547^{*}$ & 870 & 1.226 & 647 & $1.226^{* *}$ & $586^{*}$ \\
\hline $\mathrm{P}$ & 12.651 & 2.877 & $2.877^{* *}$ & $258^{*}$ & 320 & $8.882^{++}$ & $250 *$ & $4.197^{* *}$ & 577 & 2.174 & $1.995^{+}$ & $284^{*}$ & $1.995^{* *}$ & 854 \\
\hline $\mathrm{H}^{+}$ & 346 & 199 & $115^{* *}$ & 98 & $54^{*}$ & $193^{+}$ & $141^{* *}$ & 124 & $101^{*}$ & 127 & $346^{++}$ & $265^{* *}$ & 183 & $79 *$ \\
\hline $\mathrm{CO}$ & 565 & $485^{++}$ & $57^{*}$ & 57 & $415^{* *}$ & 432 & $51^{*}$ & 81 & $350 * *$ & 66 & $284^{+}$ & $284^{* *}$ & 105 & $49^{*}$ \\
\hline Argila & 157 & $58^{+}$ & $12^{*}$ & 31 & $51 * *$ & 77 & $22^{*}$ & 59 & 43 & $77 * *$ & $157^{++}$ & $44^{*}$ & $114^{* *}$ & 58 \\
\hline Silte & 121 & $61^{+}$ & $16^{*}$ & 35 & $49 * *$ & 81 & $33^{*}$ & 66 & 44 & $81 * *$ & $121^{++}$ & $32^{*}$ & 65 & $72^{* *}$ \\
\hline $\mathrm{AF}$ & 639 & $230^{+}$ & 48 & $93^{* *}$ & $41^{*}$ & $456^{++}$ & 122 & $339 * *$ & $44^{*}$ & 123 & 323 & $274^{* *}$ & $101^{*}$ & 221 \\
\hline $\mathrm{AG}$ & 555 & $198^{+}$ & $49^{*}$ & 95 & $136^{* *}$ & 487 & 143 & 343 & $130^{*}$ & $450 * *$ & $518^{++}$ & $143^{*}$ & $518^{* *}$ & 361 \\
\hline $\mathrm{AT}$ & 307 & $134^{+}$ & $48^{*}$ & 64 & $65^{* *}$ & 239 & 72 & 168 & $69 *$ & $186^{* *}$ & $307^{++}$ & 207 & $166^{*}$ & $213^{* *}$ \\
\hline
\end{tabular}

(1) *Menores valores dentro das unidades de mapeamento que compõem o compartimento; ** Maiores valores dentro das unidades de mapeamento que compõem o compartimento; ${ }^{+}$Menor valor do compartimento que compõe a área total; ${ }^{++}$Maior valor dentro do compartimento que compõe a área total. Un1: Latossolo Vermelho distrófico húmico textura muito argilosa; Un2: Latossolo Vermelho-Amarelo distrófico húmico textura argilosa; Un3: Cambissolo Húmico distrófico textura muito argilosa; Un4: associação Cambissolo Húmico distrófico latossólico textura argilosa + Cambissolo Háplico Tb distrófico textura argilosa; Un5: associação Cambissolo Háplico Tb distrófico latossólico textura argilosa + Cambissolo Húmico Alumínico latossólico textura argilosa; Un6: Cambissolo Húmico distrófico latossólico textura argilosa; Un7: Cambissolo Húmico Alumínico latossólico textura argilosa; Un8: associação Cambissolo Húmico distrófico latossólico textura argilosa + Cambissolo Háplico Tb distrófico latossólico textura argilosa; Un9: Cambissolo Húmico distrófico latossólico textura argilosa; Un10: Cambissolo Húmico distrófico latossólico textura argilosa. 
a amostragem composta. A declividade média dos compartimentos superior, médio e inferior foi de 11, 9 e $7 \%$, respectivamente. No corte apresentado na figura 2 , a variação altimétrica total do compartimento médio foi de $12 \mathrm{~m}$, e a do compartimento superior, de $20 \mathrm{~m}$

O perfil altimétrico da área total versus o teor de CO ilustra o efeito da forma do terreno (curvaturas) nos valores dos atributos (Figura 2). Nas unidades 2 e 10, com relevo mais plano, verificou-se maior homogeneidade nos teores de CO. Nos compartimentos médio e superior, os menores teores de $\mathrm{CO}$ no ho- rizonte A foram observados nas posições convexas do relevo, e o maior acúmulo de água nas posições côncavas induziu o acúmulo de matéria orgânica. Mesmo na unidade 3 do compartimento médio, que apresenta relevo suave ondulado, o encaixe de pequenas linhas de drenagem promoveu aumento nos teores de $\mathrm{CO}$ nas superfícies côncavas (Figura 2). Normalmente essa pequena diferença no relevo não seria discriminada pela amostragem composta convencional, o que poderia levar a erro na recomendação de adubação nitrogenada, quando esta é baseada nos níveis de CO.

As áreas que apresentaram maior e menor

Quadro 3. Coeficiente de variação dos atributos em área total (Total) e compartimentos inferior (composto pelas unidades de mapeamento 1,9 e 10), médio (composto pelas unidades $2,3,7$ e 8 ) e superior (composto pelas unidades 4,5 e 6$)^{(1)}$

\begin{tabular}{|c|c|c|c|c|c|c|c|c|c|c|c|c|c|c|}
\hline & Total & Inf. & Un 1 & Un 9 & Un 10 & Médio & Un 2 & Un 3 & Un 7 & Un 8 & Sup. & Un 4 & Un 5 & Un 6 \\
\hline & & & & & & & & \multicolumn{7}{|l|}{$\%$} \\
\hline pHágua & 5 & $4^{+}$ & 4 & $6^{* *}$ & $3^{*}$ & $4^{+}$ & 4 & $3^{*}$ & $5^{* *}$ & 4 & $5^{++}$ & $4^{*}$ & 5 & $6^{* *}$ \\
\hline $\mathrm{pHKCl}$ & 6 & $5^{+}$ & 5 & $4^{* *}$ & $4^{*}$ & $5^{+}$ & 5 & $4^{*}$ & 5 & $6 * *$ & $7^{++}$ & $4^{*}$ & 5 & $6 * *$ \\
\hline $\mathrm{Al}^{3+}$ & 117 & 89 & $94^{* *}$ & 80 & $49 *$ & $83^{+}$ & $56^{*}$ & $108^{* *}$ & 99 & 81 & $92^{++}$ & $91^{* *}$ & $80^{*}$ & 82 \\
\hline $\mathrm{Ca}^{2+}$ & 35 & 31 & $24^{*}$ & 25 & $39 * *$ & $24^{+}$ & $27^{*}$ & 28 & $37 * *$ & 20 & $49^{++}$ & $25^{*}$ & 48 & $55^{* *}$ \\
\hline $\mathrm{Mg}^{2+}$ & 34 & 31 & 30 & $35^{* *}$ & $26^{*}$ & $23^{+}$ & 27 & 25 & $37 * *$ & $24^{*}$ & $46^{++}$ & $18^{*}$ & 42 & $68^{* *}$ \\
\hline $\mathrm{K}^{+}$ & 78 & $71^{+}$ & 59 & $84^{* *}$ & $46^{*}$ & $80^{++}$ & $54^{*}$ & 74 & 71 & $96^{* *}$ & 74 & 77 & $84^{* *}$ & $56^{*}$ \\
\hline $\mathrm{P}$ & 99 & $59^{+}$ & $98^{* *}$ & 48 & $44^{*}$ & $105^{++}$ & $44^{* *}$ & 71 & 68 & $148 * *$ & 69 & $40 *$ & 58 & $67 * *$ \\
\hline $\mathrm{H}^{+}$ & 25 & $24^{+}$ & 25 & $22^{* *}$ & $12^{*}$ & $24^{+}$ & $29 * *$ & 21 & $18^{*}$ & 25 & $26^{++}$ & $31^{* *}$ & 29 & $16^{*}$ \\
\hline $\mathrm{CO}$ & 20 & 20 & 16 & $13^{*}$ & $29 * *$ & $19^{+}$ & $13^{*}$ & 17 & $29 * *$ & 17 & $21^{++}$ & $29 * *$ & 19 & $12^{*}$ \\
\hline Argila & 13 & $9^{+}$ & $4^{*}$ & 7 & $12^{* *}$ & 13 & $6^{*}$ & 13 & 10 & $15^{* *}$ & $14^{++}$ & $11^{*}$ & $15^{* *}$ & 13 \\
\hline Silte & 14 & $11^{+}$ & $6^{*}$ & 8 & $13^{* *}$ & $15^{++}$ & $8^{*}$ & 14 & 10 & $15^{* *}$ & 13 & $9 *$ & 13 & $14^{* *}$ \\
\hline $\mathrm{AF}$ & 29 & $21^{+}$ & 15 & $21^{* *}$ & $10^{*}$ & 24 & 23 & $25^{* *}$ & $13^{*}$ & 21 & $28^{++}$ & $29 * *$ & $21^{*}$ & 28 \\
\hline $\mathrm{AG}$ & 42 & $22^{+}$ & $13^{*}$ & 16 & $27^{* *}$ & $47^{++}$ & $24 * *$ & 36 & 27 & $60 * *$ & 45 & $29 *$ & $65^{* *}$ & 44 \\
\hline $\mathrm{AT}$ & 28 & $17^{+}$ & $13^{*}$ & $16^{* *}$ & 15 & 28 & $15^{*}$ & 23 & 14 & $32^{* *}$ & $31^{++}$ & 28 & $34^{* *}$ & $27^{*}$ \\
\hline
\end{tabular}

(1) *Menores valores dentro das unidades de mapeamento que compõem o compartimento; ** Maiores valores dentro das unidades de mapeamento que compõe o compartimento; ${ }^{+}$Menor valor do compartimento que compõe a área total; ${ }^{++}$Maior valor dentro do compartimento que compõe a área total.

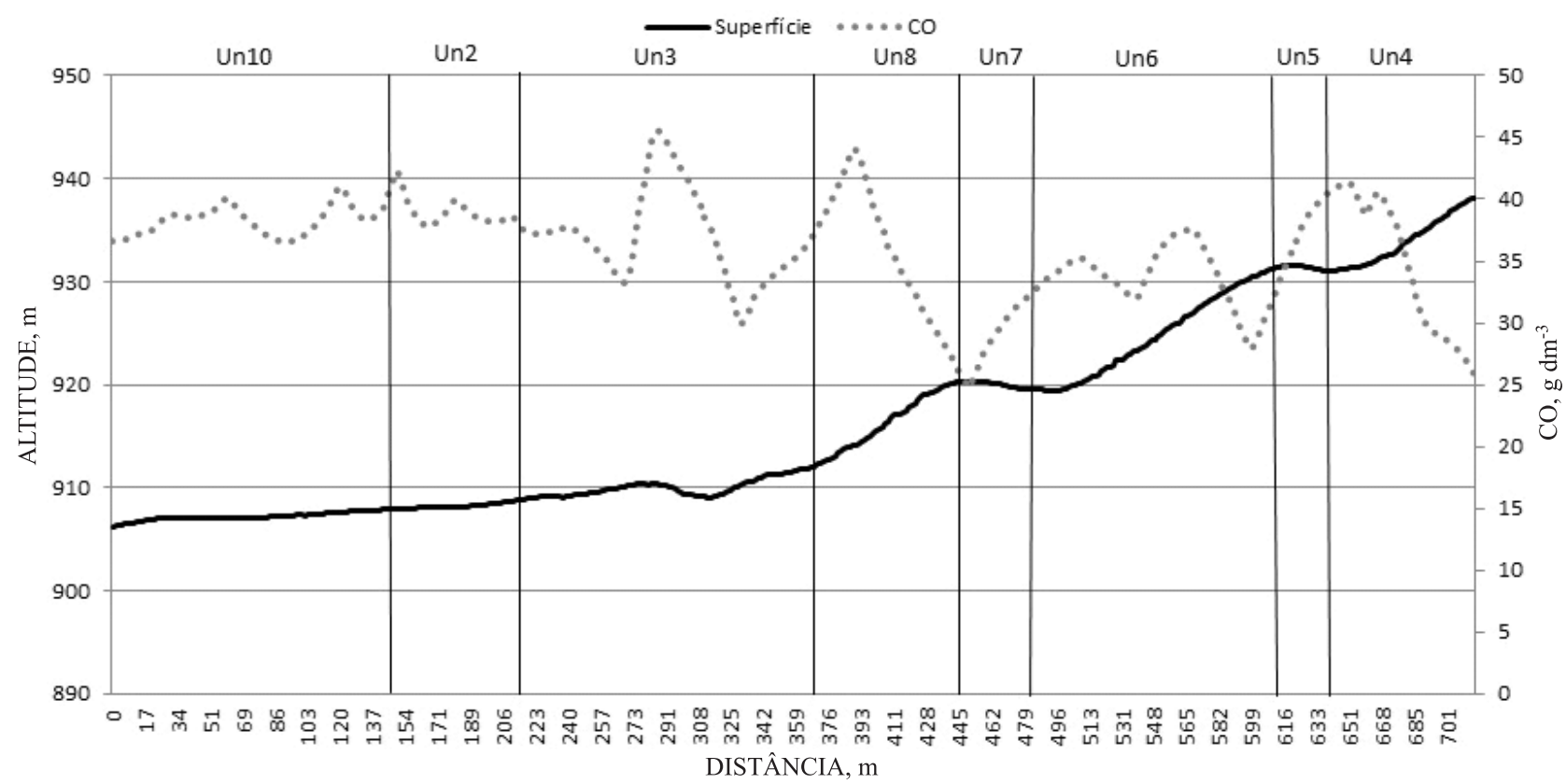

Figura 2. Perfil altimétrico da área (superfície), com a distância horizontal do perfil, unidade de mapeamento e teor de carbono em $\mathrm{g} \mathrm{dm}^{-3}$. Compartimento inferior - unidades 2 e 10; compartimento médio-unidades 2, 3, 7 e 8; compartimento superior-unidade 4, 5 e 6. 
amplitude de valores não foram as mesmas para todos os atributos (Quadro 2), indicando que, além do fator relevo, as variações intrínsecas de cada atributo foram importantes. Para área total, o atributo com maior amplitude foi o $\mathrm{P}(12.651 \%)$, seguido de $\mathrm{K}^{+}$(3.978\%) e de $\mathrm{Al}^{3+}(3.895 \%)$. A grande amplitude entre o valor máximo $\left(36,87 \mathrm{mg} \mathrm{dm}^{-3}\right)$ e o mínimo $\left(0,29 \mathrm{mg} \mathrm{dm}^{-3}\right)$ para $\mathrm{P}$ na área total foi decorrente, possivelmente, de concentração de dejeto bovino (não mais visíveis no momento da coleta), uma vez que os solos originados do argilito da Formação Guabirotuba são muito pobres nesse nutriente, com teores naturais próximos a zero (Mazza et al., 2009). Na unidade 8, a anomalia no teor de $\mathrm{P}$ em um ponto de amostragem $\left(36,87 \mathrm{mg} \mathrm{dm}^{-3}\right.$ Quadro 1) pode comprometer a representatividade do compartimento médio (amostragem em áreas mais restritas e homogêneas geomorfologicamente); os valores de CV na unidade 8 e no compartimento médio foram superiores ao CV da área total (Quadro 3), ou seja, nesse caso, quanto maiores a área e o número de amostras, maior a diluição dessas anomalias. Uma vez que em campo, na tomada de amostras simples para formar uma composta, não há como identificar se uma amostra possui valor anômalo, a utilização da média é comprometida nesses casos.

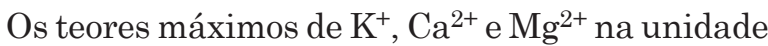
8 ficaram próximos aos observados nas demais unidades, o que confirma o enriquecimento anômalo apenas de $\mathrm{P}$ em um dos pontos de amostragem dessa unidade (Quadro 1).

No gráfico de normalidade de $\mathrm{P}$ (Figura 3a), o teor máximo da unidade 8 distanciou-se dos demais pontos de amostragem. Esse teor anômalo de $\mathrm{P}$ também contribuiu para tornar a distribuição das frequências dos dados da área total distante da distribuição normal (Figura 3b), com elevados valores de assimetria (Quadro 4) e de curtose (Quadro 5). No compartimento inferior a distribuição das frequências se aproximou da distribuição normal (Figura 4a,b), o que determinou valores de assimetria e curtose próximos a zero (Quadros 4 e 5). O valor positivo de assimetria para esse compartimento refletiu a maior concentração das observações abaixo do valor médio: maior número de observações à esquerda do gráfico da distribuição normal (Figura 4b).
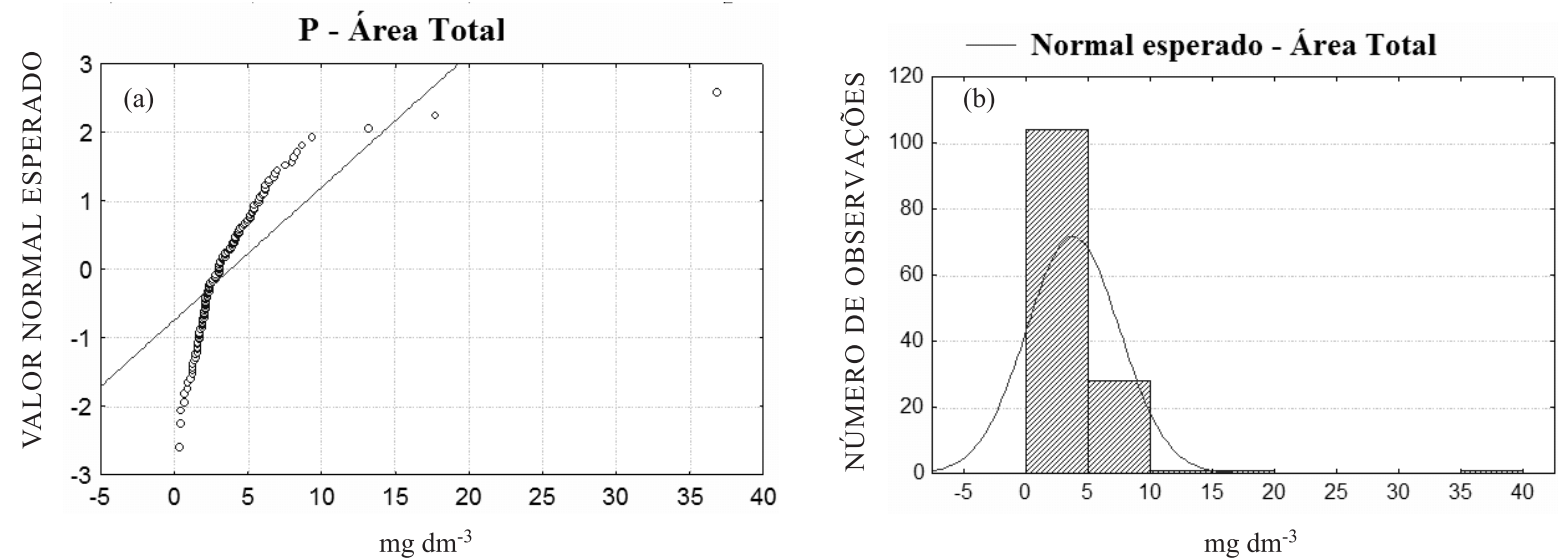

Figura 3. Gráfico de normalidade (a) e distribuição das classes de frequência (b) dos teores de $\mathbf{P}$ em área total.
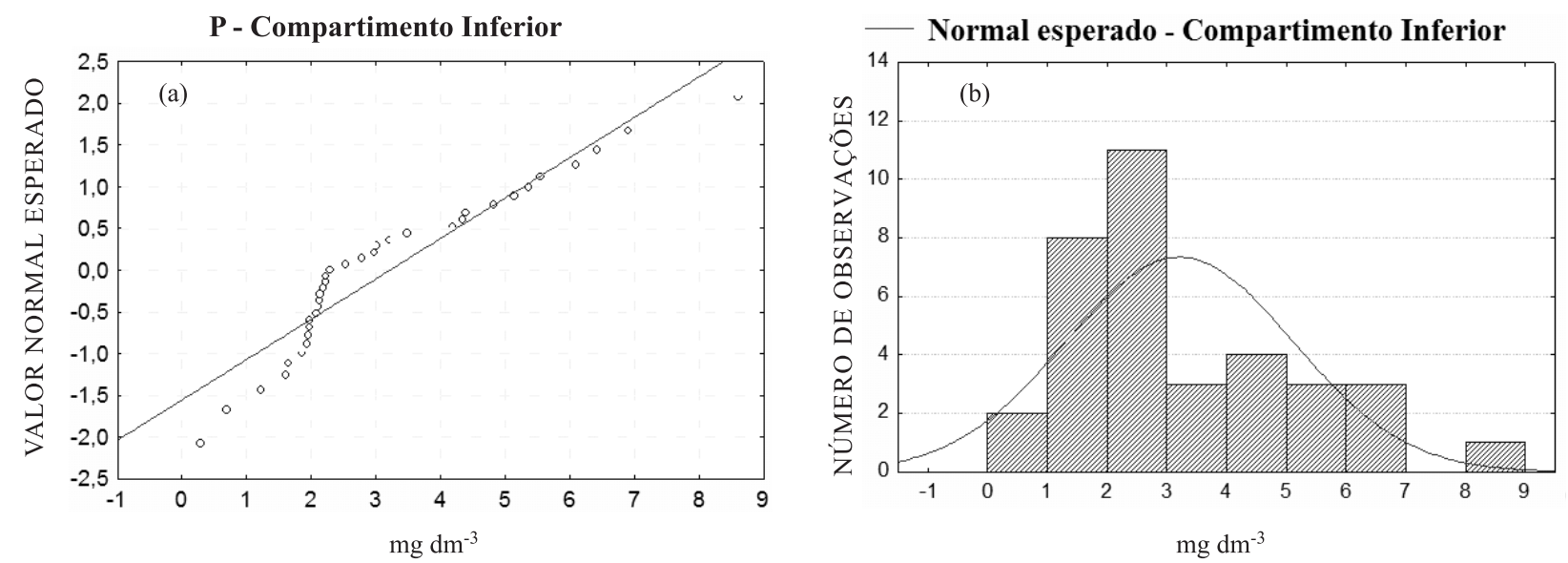

Figura 4. Gráfico de normalidade (a) e distribuição das classes de frequência (b) dos teores de $\mathbf{P}$ no compartimento inferior. 
A maioria dos atributos, principalmente para compartimento inferior, apresentou coeficientes de assimetria (Quadro 4) e de curtose (Quadro 5) mais distantes de zero, valor característico da distribuição normal. Assim, uma média aritmética não seria a medida mais adequada para representação desses atributos (Rosa Filho, 2009), ao contrário do que normalmente é realizado em amostragens compostas para adubação e calagem (Oliveira et al., 2007). Para o $\mathrm{Mg}^{2+}$, a distribuição das frequências dos dados ficou muito próxima da distribuição normal, independentemente do nível de detalhamento da amostragem.

Seguindo a mesma tendência da amplitude, os valores de CV máximo e mínimo para cada atributo dentro dos compartimentos não ocorreram nas mesmas unidades de mapeamento. Na área total, o $\mathrm{Al}^{3+}$ apresentou o maior CV (117\%), seguido de P $(99 \%)$ e de $\mathrm{K}^{+}(78 \%)$, semelhante às observações de Alvarez V. \& Garçoni M. (2003), Silva et al. (2003a,b) e Gomes et al. (2008). Uma particularidade observada por esse método de análise é que, conforme as áreas foram subdivididas, alguns compartimentos apresentam valor maior que da área total. Por exemplo, o $\mathrm{K}^{+}$apresenta $\mathrm{CV}$ de $78 \%$ para a área total e de $80 \%$ para o compartimento médio. Entre as unidades de mapeamento do compartimento médio, a unidade 8 possui CV de $96 \%$, e as demais unidades tiveram CV menores que os do compartimento. Com o elevado CV para $\mathrm{K}^{+}$no nível de maior subdivisão (unidade 8), mesmo a amostragem mais detalhada dessa gleba não garante boa representatividade da área.

Os coeficientes de correlação ( $\mathrm{r}$ ) na área total foram negativos entre $\mathrm{Al}^{3+}$ e $\mathrm{Ca}(-0,71)$ e $\mathrm{Al}^{3+}$ e $\mathrm{Mg}^{2+}$ $(-0,70)$ e positivo entre $\mathrm{Ca}^{2+}$ e $\mathrm{Mg}^{2+}(0,82)$ (Quadro 6). Dos compartimentos, o que apresentou maiores coeficientes de correlação para esses atributos foi o superior; os outros dois compartimentos apresentaram valores de $\mathrm{r}$ menores que os da área total para a maioria dos atributos (Quadros 7 e 8).

Os coeficientes de correlação altos e negativos $\mathrm{Al}^{3+}$ e $\mathrm{pH}$ em $\mathrm{KCl}$ (Quadros 7 e 8) indicam que horizontes superficiais mais intemperizados (maior $\mathrm{pH} \mathrm{KCl}$ )

Quadro 4. Coeficiente de assimetria dos atributos dentro de cada compartimento

\begin{tabular}{|c|c|c|c|c|c|c|c|c|c|c|c|c|c|c|}
\hline & Total & Inf. & Un 1 & Un 9 & Un 10 & Médio & Un 2 & Un 3 & Un 7 & Un 8 & Sup. & Un 4 & Un 5 & Un 6 \\
\hline $\mathrm{pH}$ água & 0,69 & 1,13 & $-0,87$ & 2,16 & 0,27 & 0,62 & 2,02 & 0,06 & 0,60 & 0,07 & 0,95 & 0,71 & $-0,41$ & 1,95 \\
\hline $\mathrm{pH}$ KCl & 0,34 & 0,85 & $-0,63$ & 2,10 & 0,22 & 0,48 & 0,52 & $-0,50$ & 0,38 & 0,94 & 0,46 & 0,44 & $-0,64$ & 0,69 \\
\hline $\mathrm{Al}^{3+}$ & 2,32 & 1,62 & 2,32 & 0,77 & 0,08 & 1,89 & 0,41 & 3,53 & 1,28 & 1,66 & 0,93 & 1,65 & 0,50 & 0,49 \\
\hline $\mathrm{Ca}^{2+}$ & $-0,03$ & 0,92 & $-0,24$ & $-0,19$ & 1,37 & 0,17 & $-0,12$ & $-0,05$ & $-0,51$ & $-0,09$ & 0,18 & $-0,50$ & $-0,52$ & 0,16 \\
\hline $\mathrm{Mg}^{2+}$ & $-0,26$ & $-0,32$ & $-0,18$ & $-0,42$ & 0,35 & 0,20 & 0,01 & $-0,09$ & $-0,24$ & 0,83 & 0,20 & 0,55 & $-0,66$ & 0,30 \\
\hline $\mathrm{K}^{+}$ & 1,66 & 2,66 & 2,09 & 2,46 & 1,44 & 1,45 & 0,20 & 0,91 & 1,34 & 2,14 & 1,29 & 0,84 & 1,38 & 1,30 \\
\hline $\mathrm{P}$ & 5,71 & 1,03 & 1,53 & 0,31 & 0,88 & 4,83 & 0,72 & 2,16 & 1,38 & 3,33 & 1,59 & 0,16 & 2,46 & 1,28 \\
\hline $\mathrm{H}^{+}$ & 0,66 & 0,20 & $-0,21$ & 0,12 & 0,14 & 0,53 & $-0,01$ & 0,89 & $-0,84$ & 0,81 & 1,02 & 0,68 & 4,40 & $-0,60$ \\
\hline $\mathrm{CO}$ & $-0,69$ & $-1,72$ & 0,30 & 0,47 & $-2,45$ & $-0,71$ & $-0,10$ & 0,25 & $-1,69$ & 0,80 & 0,05 & $-0,02$ & $-0,03$ & 0,54 \\
\hline Silte & 0,57 & 1,44 & 1,14 & 0,94 & 1,16 & 0,35 & 0,13 & 0,89 & $-0,55$ & $-0,26$ & 0,44 & 0,12 & 7,81 & $-0,91$ \\
\hline Argila & $-0,59$ & $-1,39$ & $-1,04$ & $-0,88$ & $-1,12$ & $-0,35$ & $-0,08$ & $-0,88$ & 0,58 & 0,22 & $-0,48$ & $-0,17$ & 7,87 & 0,95 \\
\hline $\mathrm{AF}$ & 0,80 & $-0,44$ & 2,47 & $-0,31$ & 1,85 & 0,36 & $-0,12$ & 0,17 & 0,30 & 1,20 & 0,36 & $-0,34$ & $-0,73$ & 0,18 \\
\hline $\mathrm{AG}$ & 1,98 & 1,98 & $-0,01$ & $-0,09$ & 2,16 & 1,79 & 2,22 & 1,82 & 0,64 & 0,89 & 1,81 & 0,70 & 3,98 & 1,25 \\
\hline $\mathrm{AT}$ & 1,01 & 1,13 & 1,89 & $-0,25$ & 2,63 & 0,96 & $-0,21$ & 0,78 & 0,83 & 0,37 & 0,68 & 0,05 & 1,99 & $-0,11$ \\
\hline
\end{tabular}

Quadro 5. Coeficiente de curtose dos atributos dentro de cada compartimento

\begin{tabular}{|c|c|c|c|c|c|c|c|c|c|c|c|c|c|c|}
\hline & Total & Inf. & Un 1 & Un 9 & Un 10 & Médio & Un 2 & Un 3 & Un 7 & Un 8 & Sup. & Un 4 & Un 5 & Un 6 \\
\hline pHágua & 1,03 & 4,07 & 0,21 & 5,63 & 1,71 & 0,70 & 5,94 & 0,93 & 1,49 & $-0,34$ & 1,20 & 1,06 & $-0,41$ & 4,71 \\
\hline $\mathrm{pH}_{\mathrm{KCl}}$ & 0,33 & 1,62 & $-0,02$ & 5,78 & $-0,63$ & 1,11 & $-0,96$ & 1,12 & $-0,12$ & 1,84 & $-0,79$ & 0,11 & $-0,64$ & $-1,29$ \\
\hline $\mathrm{Al}^{3+}$ & 5,60 & 1,77 & 5,84 & $-0,89$ & $-1,62$ & 4,24 & $-1,12$ & 14,57 & 0,88 & 1,71 & $-0,19$ & 2,68 & 0,50 & $-0,93$ \\
\hline $\mathrm{Ca}^{2+}$ & 0,29 & 1,54 & $-0,97$ & $-0,61$ & 1,17 & $-0,34$ & $-0,33$ & $-0,47$ & $-0,78$ & $-0,91$ & $-1,21$ & $-0,20$ & $-0,52$ & $-1,67$ \\
\hline $\mathrm{Mg}^{2+}$ & $-0,19$ & $-0,12$ & $-0,50$ & 0,34 & $-1,18$ & $-0,17$ & $-0,93$ & 0,47 & $-0,80$ & 1,15 & $-0,65$ & 0,43 & $-0,66$ & $-1,81$ \\
\hline $\mathrm{K}^{+}$ & 2,42 & 9,59 & 4,80 & 7,28 & 1,23 & 1,39 & $-1,20$ & $-0,30$ & 1,15 & 4,29 & 1,00 & $-1,07$ & 1,38 & 1,03 \\
\hline $\mathrm{P}$ & 45,96 & 0,61 & 1,80 & $-1,58$ & 0,37 & 28,82 & $-1,17$ & 5,71 & 0,95 & 11,51 & 3,05 & $-1,45$ & 2,46 & 0,90 \\
\hline $\mathrm{H}^{+}$ & 1,37 & $-0,09$ & $-0,64$ & $-0,97$ & 0,00 & $-0,09$ & $-1,22$ & 0,69 & 0,70 & 0,06 & 3,56 & 1,53 & 4,40 & $-0,09$ \\
\hline $\mathrm{CO}$ & 2,73 & 5,34 & $-0,65$ & 0,45 & 6,48 & 2,85 & $-1,50$ & $-0,82$ & 3,07 & $-0,13$ & 1,50 & 1,08 & $-0,03$ & $-0,54$ \\
\hline Silte & 0,45 & 2,65 & 0,34 & 1,50 & 0,69 & $-0,67$ & $-0,91$ & $-0,11$ & 0,71 & 0,72 & 2,82 & $-0,95$ & 7,81 & 1,12 \\
\hline Argila & 0,55 & 2,45 & $-0,15$ & 1,29 & 0,66 & $-0,66$ & $-0,96$ & $-0,15$ & 0,69 & 0,66 & 2,87 & $-0,89$ & 7,87 & 1,25 \\
\hline $\mathrm{AF}$ & 1,58 & 0,45 & 6,46 & $-1,23$ & 4,41 & 1,28 & $-1,23$ & 1,69 & $-1,36$ & 3,02 & 0,61 & 0,30 & $-0,73$ & 0,29 \\
\hline$A G$ & 4,73 & 6,21 & $-0,55$ & 1,00 & 5,72 & 3,09 & 6,55 & 5,33 & 0,42 & $-0,69$ & 4,45 & $-0,26$ & 3,98 & 1,18 \\
\hline $\mathrm{AT}$ & 1,23 & 3,87 & 4,31 & $-1,26$ & 7,75 & 0,60 & $-0,97$ & 0,84 & 0,91 & $-1,04$ & 0,18 & $-0,21$ & 1,99 & $-0,20$ \\
\hline
\end{tabular}


Quadro 6. Valores de $p$ para o teste de normalidade Shapiro-Wilk ${ }^{(1)}$

\begin{tabular}{|c|c|c|c|c|c|c|c|c|c|c|c|c|c|c|}
\hline & Total & Inf. & Un 1 & Un 9 & Un 10 & Médio & Un 2 & Un 3 & Un 7 & Un 8 & Sup. & Un 4 & Un 5 & Un 6 \\
\hline P & 00 & 0.01 & $63 *$ & 0.00 & $34^{*}$ & $0.42^{*}$ & 0.00 & $0.93^{*}$ & $0.40^{*}$ & $0.89^{*}$ & 0.05 & $0.68^{*}$ & $0.70^{*}$ & 0.01 \\
\hline $\mathrm{pH}_{\mathrm{K}}$ & $0.14^{*}$ & 0.09 & $0.75^{x}$ & 0.00 & $0.91^{*}$ & $0.53^{*}$ & $0.18^{*}$ & $0.32^{*}$ & $0.89^{*}$ & $0.25^{*}$ & 0.06 & $0.90^{*}$ & $0.41^{*}$ & 0.02 \\
\hline $\mathrm{Al}^{3+}$ & 0.00 & 0.00 & .00 & 0.04 & 0.06 & 0.00 & $0.21^{*}$ & 0.00 & 0.04 & 0.00 & 0.00 & 0.01 & 0.07 & $0.19^{*}$ \\
\hline $\mathrm{Ca}^{2+}$ & & 0.04 & . & $095 *$ & & 0 8* & $0.72^{*}$ & $0.83^{*}$ & $0.21^{*}$ & $0.20^{*}$ & 0.05 & $0.64^{*}$ & & $0.11^{*}$ \\
\hline $\mathrm{Mg}^{2+}$ & $0.18^{*}$ & $0.85^{*}$ & $0.89^{*}$ & $0.99^{*}$ & $0.60^{*}$ & $0.56^{*}$ & $0.82^{*}$ & $0.69^{*}$ & $0.36^{*}$ & $0.74^{*}$ & $0.38^{*}$ & $0.64^{*}$ & $0.58^{*}$ & 0.04 \\
\hline $\mathrm{K}^{+}$ & 0.00 & 0.00 & 01 & 000 & 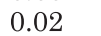 & 000 & $0.33^{*}$ & 0.01 & 0.02 & 0.00 & 0.00 & 0.01 & 0.00 & 0.04 \\
\hline $\mathrm{P}$ & 0 & 0.0 & 0.0 & 0.0 & 0. & 0. & 0.02 & 0 & 0.0 & 0.0 & 0.0 & $0.24^{*}$ & $0.21^{*}$ & 0.03 \\
\hline $\mathrm{H}^{+}$ & 0.02 & $0.83^{*}$ & $0.82^{*}$ & $0.65^{*}$ & $1.00^{*}$ & $0.39^{*}$ & $0.31^{*}$ & $0.20^{*}$ & $0.67^{*}$ & $0.20^{*}$ & 0.01 & $0.68^{*}$ & 0.02 & $0.71^{*}$ \\
\hline $\mathrm{CO}$ & & 0.00 & $089 *$ & $0.87^{*}$ & 0.00 & 0.01 & $0.17^{*}$ & $0.37^{*}$ & 0.02 & & $0.31^{*}$ & $0.89^{*}$ & $0.93^{*}$ & $0.41^{*}$ \\
\hline Silte & & 0.0 & 0.09 & $0.28^{*}$ & & 0. & $0.73^{*}$ & 0.01 & $0.80^{*}$ & $0.71^{*}$ & 0.05 & $0.87^{*}$ & 0.00 & $0.14^{*}$ \\
\hline Argila & 0.02 & 0.00 & 0.11 & $0.37^{*}$ & 0.07 & $0.17^{*}$ & $0.78^{*}$ & 0.01 & $0.77^{*}$ & $0.70^{*}$ & 0.04 & $0.76^{*}$ & 0.00 & $0.12^{*}$ \\
\hline $\mathrm{AF}$ & 0.00 & $0.74^{*}$ & 0.00 & $0.32^{*}$ & 0.03 & $0.21^{*}$ & $0.21^{*}$ & 0.03 & $0.27^{*}$ & $0.17^{*}$ & $0.35^{*}$ & $0.43^{*}$ & $0.87^{*}$ & $1.00^{*}$ \\
\hline $\mathrm{AG}$ & 0 & 0.00 & 07 & $0.20^{*}$ & & 0.00 & 0.00 & 0. & $0.21^{*}$ & 0.02 & 0.0 & $0.37^{*}$ & 0.00 & 0.07 \\
\hline $\mathrm{AT}$ & 0.00 & 0.02 & 0.03 & $0.42^{*}$ & 0.00 & 0.01 & $0.68^{*}$ & $0.31^{*}$ & $0.45^{*}$ & $0.65^{*}$ & $0.20^{*}$ & $0.96^{*}$ & 0.01 & $0.88^{*}$ \\
\hline
\end{tabular}

(1) *: atributos com distribuição normal a $5 \%$.

Quadro 7. Matriz de correlação dos atributos em área total $(n=135)^{(1)}$

\begin{tabular}{|c|c|c|c|c|c|c|c|c|c|c|c|c|c|}
\hline & pH $H_{\text {água }}$ & $\mathrm{pH}_{\mathrm{KCl}}$ & $\mathrm{Al}^{3+}$ & $\mathrm{Ca}^{2+}$ & $\mathrm{Mg}^{2+}$ & $\mathbf{K}^{+}$ & $\mathbf{P}$ & $\mathbf{H}^{+}$ & $\mathrm{CO}$ & Silte & Argila & $\mathbf{A F}$ & $\mathrm{AG}$ \\
\hline $\mathrm{pH}_{\mathrm{KCl}}$ & $0,65^{* *}$ & & & & & & & & & & & & \\
\hline $\mathrm{Al}^{3+}$ & $-0,51^{* *}$ & $-0,70 * *$ & & & & & & & & & & & \\
\hline $\mathrm{Ca}^{2+}$ & $0,51^{* *}$ & $0,65^{* *}$ & $-0,71^{* *}$ & & & & & & & & & & \\
\hline $\mathrm{Mg}^{2+}$ & $0,49 * *$ & $0,64^{* *}$ & $-0,70 * *$ & $0,82^{* *}$ & & & & & & & & & \\
\hline $\mathrm{K}^{+}$ & $0,19 *$ & 0,14 & $-0,10$ & 0,10 & 0,06 & & & & & & & & \\
\hline $\mathrm{P}$ & 0,12 & $0,26^{* *}$ & $-0,17$ & $0,26^{* *}$ & 0,12 & $0,50 * *$ & & & & & & & \\
\hline $\mathrm{H}^{+}$ & $-0,50 * *$ & $-0,63^{* *}$ & $0,46^{* *}$ & $-0,31^{* *}$ & $-0,32^{* *}$ & $-0,04$ & $-0,04$ & & & & & & \\
\hline $\mathrm{CO}$ & $-0,13$ & $-0,07$ & 0,04 & $0,24^{* *}$ & 0,16 & 0,15 & 0,13 & $0,50 * *$ & & & & & \\
\hline Silte & 0,15 & 0,06 & $-0,03$ & $-0,03$ & $-0,03$ & $-0,08$ & $-0,05$ & $-0,01$ & $-0,09$ & & & & \\
\hline Argila & $-0,15$ & $-0,07$ & 0,04 & 0,03 & 0,04 & 0,08 & 0,05 & 0,02 & 0,10 & $-1,00 * *$ & & & \\
\hline $\mathrm{AF}$ & 0,02 & 0,14 & $-0,02$ & $-0,14$ & $-0,22^{*}$ & $-0,13$ & $-0,17^{*}$ & $-0,14$ & $-0,18^{*}$ & $0,50 * *$ & $-0,52^{* *}$ & & \\
\hline $\mathrm{AG}$ & 0,14 & $0,25^{* *}$ & $-0,11$ & 0,00 & $-0,07$ & 0,00 & 0,17 & $-0,23 * *$ & $-0,15$ & $0,48^{* *}$ & $-0,50 * *$ & $0,30 * *$ & \\
\hline $\mathrm{AT}$ & 0,10 & $0,24^{* *}$ & $-0,08$ & $-0,08$ & $-0,18^{*}$ & $-0,08$ & 0,00 & $-0,23 * *$ & $-0,21^{*}$ & $0,61^{* *}$ & $-0,64^{* *}$ & $0,80^{* *}$ & $0,82^{*}$ \\
\hline
\end{tabular}

(1) * e ${ }^{* *}$ : coeficientes de correlação significativos a 5 e $1 \%$, respectivamente, pelo teste t.

tendem a apresentar menor CTC e maior possibilidade de estabilização do Al na estrutura de óxidos secundários (gibbsita) (Silva et al., 2008; Motta \& Melo, 2009). No compartimento inferior, com solos mais desenvolvidos, apesar dos altos valores de amplitude e dos coeficientes de variação (Quadros $2 \mathrm{e}$ 3 ), os teores máximos de $\mathrm{Al}^{3+}$ foram inferiores aos observados nos demais compartimentos (Quadro 1), o que confirma a relação negativa entre grau de intemperismo e acidez potencial trocável do solo (Bohn et al., 1979; Motta \& Melo, 2009). Por estar em uma área de preservação ambiental (APA do rio Iraí), não se usam insumos agrícolas na Fazenda Experimental da UFPR, o que descarta a possível relação inversa entre teores de $\mathrm{Al}^{3+}$ e correção dos solos.

A areia fina e areia grossa na área total foram os atributos físicos do solo que apresentaram maior variabilidade (Quadro 2), com amplitudes de valores de 639 e $555 \%$, respectivamente. Das unidades de mapeamento, a unidade 5 apresentou os maiores valores de amplitude e coeficiente de variação para areia grossa (Quadros 2 e 3). As diferentes declividades da área também influenciaram na variabilidade dos atributos físicos, sendo as menores amplitudes e CV observados no compartimento inferior. A argila não apresentou grande variabilidade, com coeficiente de assimetria negativo (Quadro 4) - comportamento também observado por Montezano et al. (2006). O teor máximo de argila foi de $670 \mathrm{~g} \mathrm{~kg}^{-1}$ (Quadro 1), compatível com rocha de origem. Mesmo sendo um dos atributos mais estáveis do solo, apresentando CV na faixa de média variabilidade (Vieira et al., 2007), localmente, na Formação Guabirotuba, verificam-se lentes de arenito Arcósio (Salamuni \& Stellfeld, 2001), o que pode resultar em maiores teores de areia no solo.

Os coeficientes de assimetria e curtose para os atributos físicos, em sua maioria, não apresentaram distribuição similar à normal, porém mostraram menor variabilidade quando comparados com os atributos químicos da mesma área. As frações granulométricas são os atributos mais estáveis do solo, sendo sua variabilidade decorrente da variação natural do solo (Montezano et al., 2006; Vieira et al., 2007), apresentando $\mathrm{CV}$ na faixa de média variabilidade. 
Quadro 8. Matriz de correlação dos atributos nos compartimentos inferior, médio e superior ${ }^{(1)}$

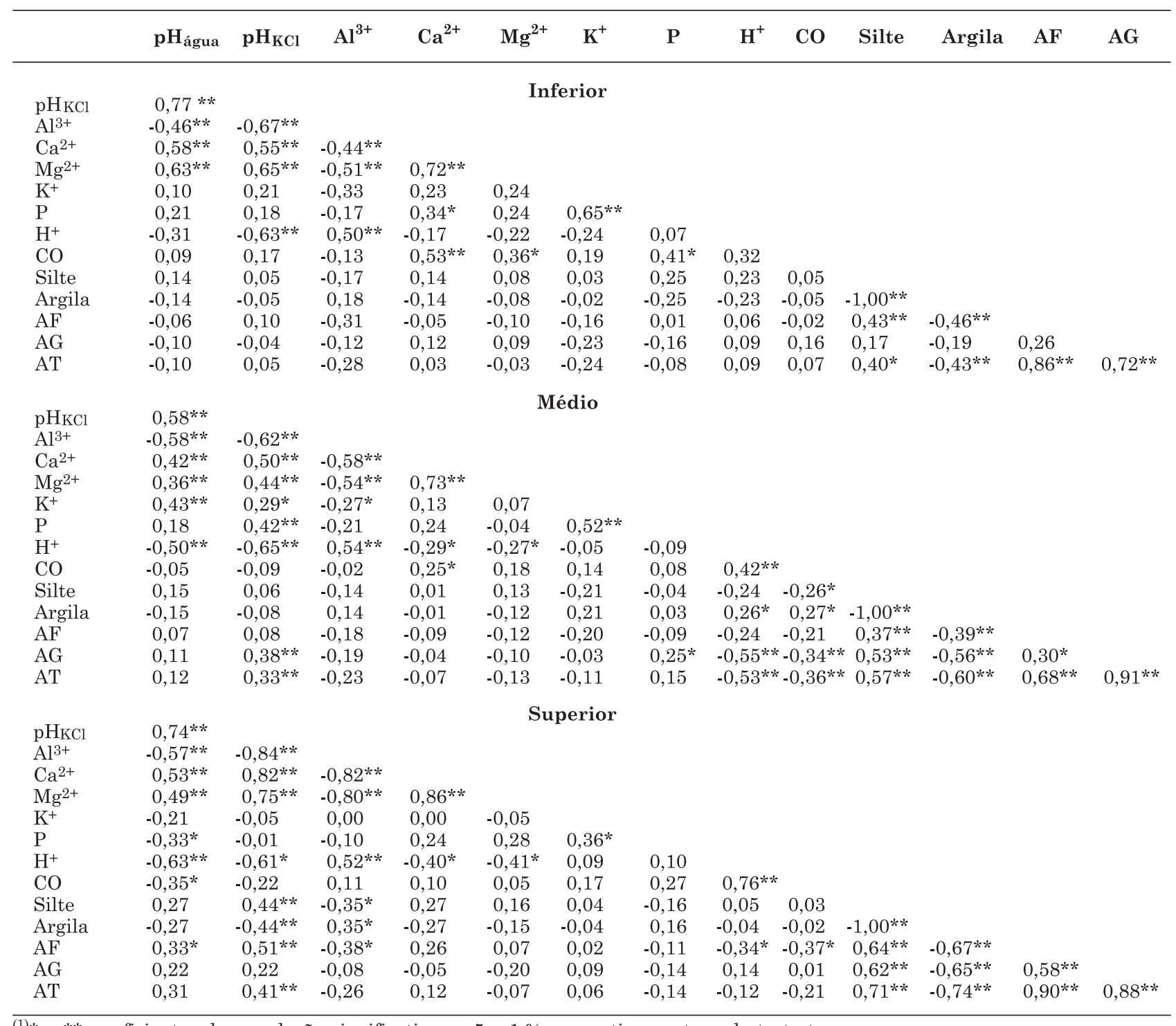

$\overline{(1) *} \mathrm{e}^{* *}$ : coeficientes de correlação significativos a 5 e $1 \%$, respectivamente, pelo teste t.

Os teste de Shapiro-Wilk indicou que, na área total, apenas $\mathrm{pH}_{\mathrm{KCl}}, \mathrm{Ca}^{2+}$ e $\mathrm{Mg}^{2+}$ tiveram distribuição similar à normal (Quadro 6). Para o $\mathrm{Al}^{3+}$, observouse distribuição normal apenas nas unidades Un2 e Un6; para o P, nas unidades Un10, Un4 e Un5; e para $\mathrm{K}^{+}$, apenas na unidade Un2. De maneira geral, as unidades de mapeamento tiveram distribuição mais próxima da normal, com destaque para a Un4, que apresentou 12 dos 14 atributos estudados nessa condição.

\section{CONCLUSÕES}

1. Com a divisão da área em nível maior de detalhe, a variação da maioria dos atributos reduziu significativamente. Contudo, em áreas com relevo mais acidentado, mesmo a coleta de amostra composta em compartimentos geomorfológicos ou em unidades de mapeamento não garantiu a qualidade da amostragem.

2. A ocorrência de linhas de drenagem nas encostas induziu o aumento local nos teores de C orgânico, limitando sua representatividade.

3. Na área total, os maiores coeficientes de variação foram observados para $\mathrm{Al}^{3+}, \mathrm{P}^{\mathrm{e}} \mathrm{K}^{+}(117,99$ e $78 \%$ respectivamente). A ocorrência de teor anômalo de $\mathrm{P}$ na unidade de mapeamento 8 comprometeu seriamente a amostragem composta do compartimento médio da paisagem.

4. Os valores para a maioria dos atributos não seguiram distribuição normal na área total e nos compartimentos, porém a subdivisão da área em 
unidades de mapeamento resultou numa distribuição normal para maior número de atributos, com destaque para a Un4, que apresentou 12 dos 14 atributos estudados com distribuição normal.

\section{LITERATURA CITADA}

ALVAREZ V., V.H. \& GUARÇONI M., A. Variabilidade horizontal da fertilidade do solo em sistema de plantio direto. R. Bras. Ci. Solo. 27:297-310, 2003.

AMARO FILHO, J.; NEGREIROS, R.F.D.; ASSIS JÚNIOR, R.N. \& MOTA, J.C.A. Amostragem e variabilidade espacial de atributos físicos de um Latossolo Vermelho em Mossoró, RN. R. Bras. Ci. Solo, 31:415-422, 2007.

BARBAR, L.C. \& MELO, V.F. Variabilidade das características químicas e mineralógicas de solos da região de Curitiba (PR). Sci. Agr., 9:187-197, 2008.

BOHN, H.L.; McNEAL, B.L. \& OCONNOR, G.A. Soil chemistry. New York, John Wiley \& Sons, 1979. 329p.

BRUS, D.J. \& NOIJ, I.G.A.M. Designing sampling schemes for effect monitoring of nutriente leaching from agricultural soils. Europ. J. Soil Sci., 59:292-303, 2008.

CANTARUTTI, R.B.; ALVAREZ V., V.H. \& RIBEIRO, A.C. Amostragem do solo. In: RIBEIRO, A.C.; GUIMARÃES, P.T.G. \& ALVAREZ V., V.H., eds. Recomendação para o uso de corretivos e fertilizantes em Minas Gerais ( $5^{a}$ aproximação). Viçosa, MG, Comissão de Fertilidade do Solo do Estado de Minas Gerais, 1999. p.13-20.

CARVALHO, J.R.P.; SILVEIRA, P.M. \& VIEIRA, S.R. Geoestatística na determinação da variabilidade espacial de características químicas do solo sob diferentes preparos. Pesq. Agropec. Bras., 37:1151-1159, 2002.

EMPRESA BRASILEIRA DE PESQUISA AGROPECUÁRIA EMBRAPA. Levantamento de reconhecimento dos solos do Estado do Paraná. Londrina, IAPAR, 1984. Tomo I.

EMPRESA BRASILEIRA DE PESQUISA AGROPECUÁRIA EMBRAPA. Manual de métodos de análise de solo. 2.ed. Rio de Janeiro, 1997. 212p.

GUARÇONI M., A.; ALVAREZ V., V.H.; NOVAIS, R.F.; CANTARUTTI, R.B.; LEITE, H.G. \& FREIRE, F.M Diâmetro de trado necessário à coleta de amostra num Cambissolo sob plantio direto ou sob plantio convencional antes ou depois da aração. R. Bras. Ci. Solo, 31:947-959, 2007.

GOMES, J.B.V.; BOLFE, E.L.; CURI, N.; FONTES, H.R.; BARRETO, A.C. \& VIANA, R.D. Variabilidade espacial de atributos do solo em unidades de manejo em área piloto de produção integrada de coco. R. Bras. Ci. Solo, 32:2471-2482, 2008 .

GUEDES FILHO, O.; VIEIRA, S.R.; CHIBA, M.K.; NAGUMO, H. \& DECHEN, S.C.F. Spatial and temporal variability of crop yield and some Rhodic Hapludox properties under no-tillage. R. Bras. Ci. Solo, 34:1-14, 2010.
KRAEMER, G.B. Variabilidade espacial dos atributos na delimitação das unidades de mapeamento. Curitiba, Universidade Federal do Paraná, 2007. 101p. (Tese de Mestrado)

LAMBKIN, D.; NORTCLIFF, S. \& WHITE, T. The importance of precision in sampling sludges, biowastes and treated soils in a regulatory framework. Trends Anal. Chem., 23:704-715, 2004.

LIN, H.; WHEELER, D.; BELL, J. \& WILDING, L. Assessment of soil spatial variability at multiple scales. Ecol. Modeling, 182:271-290, 2005.

MACHADO, L.O.; LANA, A.M.Q.; LANA, R.M.Q.; GUIMARÃES, E.C. \& FERREIRA, C.V. Variabilidade espacial de atributos químicos do solo em áreas sob sistema plantio convencional. R. Bras. Ci. Solo, 31:591-599, 2007.

MAZZA, L.M.; PÔGGERE, G.C.; FERRARO, F.P.; RIBEIRO, C.B.; CHEROBIM, V.F.; MOTTA, A.C. \& MORAES, A. Adubação nitrogenada na produtividade e composição química do capim Mombaça no primeiro planalto paranaense. Sci. Agr., 10:257-265, 2009.

MONTANARI, R.; MARQUES JÚNIOR, J.; PEREIRA, G.T. \& SOUZA, Z.M. Forma da paisagem como critério para otimização amostral de Latossolos sob cultivo de cana-deaçúcar. Pesq. Agropec. Bras., 40:69-77, 2005.

MONTEZANO, Z.F.; CORAZZA, E.J. \& MURAOKA, T. Variabilidade espacial da fertilidade do solo em área cultivada e manejada homogeneamente. R. Bras. Ci. Solo, 30:839-847, 2006.

MOTTA, A.C.V. \& MELO, V.F. Química dos solos ácidos. In: MELO, V.F. \& ALLEONI, L.R.F., eds. Química e mineralogia do solo: Aplicações. Viçosa, MG, Sociedade Brasileira de Ciência do Solo, 2009. Parte 2. p.313-380.

OLIVEIRA, F.H.T.; ARRUDA, J.A.; SILVA, I.F. \& ALVES, J.C. Amostragem para avaliação da fertilidade do solo em função do instrumento de coleta das amostras e de tipos de preparo do solo. R. Bras. Ci. Solo, 31:973-983, 2007.

PAULETTI, V.; MOTTA, A.C.V.; SERRAT, B.M.; FAVARETTO, N. \& ANJOS, A. Atributos químicos de um Latossolo Bruno sob sistema de plantio direto em função da estratégia de adubação e do método de amostragem de solo. R. Bras. Ci. Solo, 33:581-590, 2009.

ROSA FILHO, G.; CARVALHO, M.P.; ANDREOTTI, M.; MONTANARI, R.; BINOTI, F.F.S. \& GIOIA, M.T. Variabilidade da produtividade da soja em função de atributos físicos de um Latossolo Vermelho distroférrico sob plantio direto. R. Bras. Ci. Solo, 33:283-293, 2009.

SALAMUNI, E. \& STELLFELD, M.C. Banco de dados geológicos geo-referenciados da Bacia Sedimentar de Curitiba (PR) como base de sistema de informação geográfica (SIG). B. Paranaense Geoci., 49:21-32, 2001.

SANCHEZ, R.B.; MARQUES JÚNIOR, J.; SOUZA, Z.M.; PEREIRA, G.T. \& MARTINS FILHO, M.V. Variabilidade espacial de atributos do solo e de fatores de erosão em diferentes pedoformas. Bragantia, 68:1095-1103, 2009.

SILVA, P.C.M. \& CHAVES, L.H.G. Avaliação e Variabilidade espacial de fósforo, potássio e matéria orgânica em Alissolos. R. Bras. Eng. Agric. Amb., 5:431-436, 2001. 
SILVA, M.A.G.; MUNIZ, A.S.; SENGIK, E.; MATA, J.D.V.; CARISSIMI, C. \& CEGANA, A.C. Amostragem e variabilidade nos atributos de fertilidade em um Latossolo sob plantio direto em São Miguel do Iguaçu, Estado do Paraná. Acta Sci.: Agron., 25:243-248, 2003a.

SILVA, V.R.; REICHERT, J.M.; STORK, L. \& FEIJÓ, S. Variabilidade espacial das características químicas do solo e produtividade de milho em um Argissolo VermelhoAmarelo distrófico arênico. R. Bras. Ci. Solo, 27:1013$1020,2003 \mathrm{~b}$.

SILVA, V.; MOTTA, A.C.; MELO, V.F. \& LIMA, V.C. Variáveis de acidez em função da mineralogia da fração argila do solo. R. Bras. Ci. Solo, 32:551-559, 2008.

SILVA, S.A.; LIMA, J.S.S.; XAVIER, A.C. \& TEIXEIRA, M.M. Variabilidade espacial de atributos químicos de um Latossolo Vermelho-Amarelo húmico cultivado com café. R. Bras. Ci. Solo, 34:15-22, 2010.

SILVEIRA, P.M.; ZIMMERMANN, P.J.P.; SILVA, S.C. \& CUNHA, A.A. Amostragem e variabilidade espacial de características químicas de um Latossolo submetido a diferentes sistemas de preparo. Pesq. Agropec. Bras, 35:2057-2064, 2000

SNEDECOR, G.W. \& COCHRAN, W.G. Statistical methods. 6.ed. Ames, Iowa State University, 1967. 593p.

SOCIEDADE BRASILEIRA DE CIÊNCIA DO SOLO - SBCS. Manual de adubação e calagem para os Estados do Rio Grande do Sul e de Santa Catarina. 10.ed.- Porto Alegre, 2004.

SOUZA, L.S.; COGO, N.P. \& VIEIRA, S.R. Variabilidade de propriedades físicas e químicas do solo em um pomar cítrico. R. Bras. Ci. Solo, 21:367-372, 1997

SOUZA, E.G.; JOHANN, J.A.; ROCHA, J.V.; RIBEIRO, S.R.A.; SILVA, M.S.; URIBE-OPAZO, M.A.; MOLIN, J.P.; OLIVEIRA, E.F. \& NÓBREGA, L.H.P. Variabilidade espacial dos atributos químicos do solo em um Latossolo Roxo distrófico da região de Cascavel - PR. Eng. Agríc., 18:80-92, 1999.
SOUZA, C.K.; MARQUES JÚNIOR, J.; MARTINS FILHO, M.V. \& PEREIRA, G.T. Influência do relevo e erosão na variabilidade espacial de um Latossolo em Jaboticabal (SP). R. Bras. Ci. Solo, 27:1067-1074, 2003.

SOUZA, Z.M.; MARQUES JÚNIOR, J.; PEREIRA, G.T. \& BARBIERI, D.M. Smal relief shape variation influence spatial variability of soil chemical attributes. Sci. Agric., 63:161-168, 2006.

STATSOFT. Statistica for Windows. v.8.0. Tulsa, 2007.

VANNI, S.M. Modelos de regressão: Estatística aplicada. São Paulo, Legmar Informática, 1998. 177p.

VIEIRA, V.A.S.; MELLO, C.R. \& LIMA, J.M. Variabilidade espacial de atributos físicos do solo em uma microbacia hidrográfica. Ci. Agrotec., 31:1477-1485, 2007.

WANG, Y.; FENG, N.; LI, T.; ZHANG XI, Z. \& LIAO, G. Spatial variability of soil cation exchange capacity in Hilly tea plantation soils under different sampling scales. Agric. Sci. China, 7:96-103, 2008.

WARRICK, A.W. \& NIELSEN, D.R. Spatial variability of soil physical properties in the field. In: HILLEL, D., ed. Applications of soil physics. New York, Academic Press, 1980. p.319-344.

WEINDORF, D.C. \& ZHU, Y. Spatial variability of soil properties at Capulin volcano, New Mexico, USA: Implications for sampling strategy. Pedosphere, 20:185197,2010 .

ZORZI, P.; BARBIZZI, S.; BELLI, M.; FAJGELJ, A.; JACIMOVIC, R.; JERAN, Z.SANSONE, H. \& PERK, M. Soil sampling reference site: The challenge is defining reference material for sampling. Appl. Rad. Isotopes, $66: 1588-1591,2008$. 